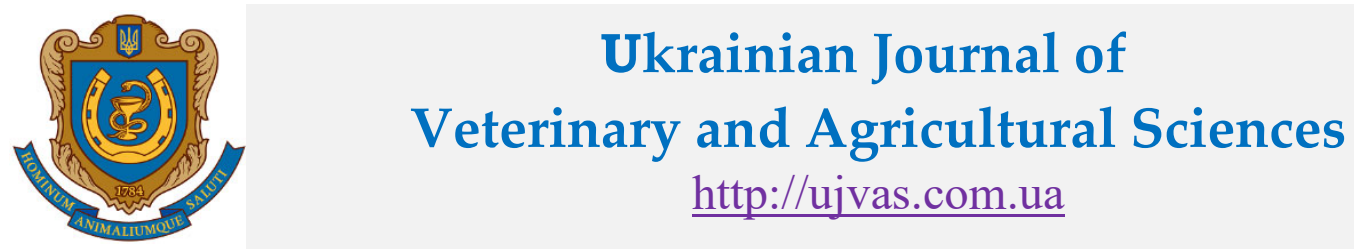

Stepan Gzhytskyi National University of Veterinary Medicine and Biotechnologies Lviv

\begin{tabular}{r|l|ll} 
original article & UDC 619:636.5/6:616.98 & doi: 10.32718/ujvas4-2.08 & Number 2
\end{tabular}

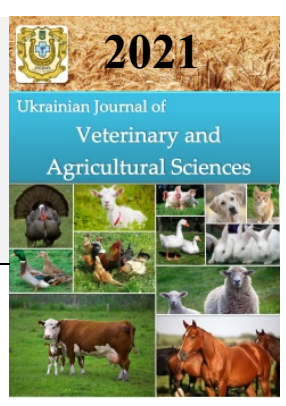

\title{
Prevalence of some common bacterial diseases in commercial poultry farm
}

Sharna Halder ${ }^{1}$, Shubhagata Das ${ }^{1}$, Sabuj Kanti Nath², Swarup Kumar Kundu ${ }^{3 *}$, Md. Sirazul Islam4, Sharmin Chowdhury ${ }^{4}$, Md. Masuduzzaman ${ }^{4}$

${ }^{I}$ Department of Pathology and Parasitology, Chattogram Veterinary and Animal Sciences University

${ }^{2}$ Department of Animal Nutrition, Faculty of Veterinary, Animal and Biomedical Sciences, Khulna Agricultural University,

Khulna-9202, Bangladesh

${ }^{3}$ Department of Anatomy and Histology, Faculty of Veterinary, Animal and Biomedical Sciences, Khulna Agricultural University, Khulna-9202, Bangladesh

${ }^{4}$ Department of Pathology and Parasitology, Chattogram Veterinary and Animal Sciences University

\begin{tabular}{l} 
Article info \\
Received 07.06.2021 \\
Received in revised form \\
15.08.2021 \\
Accepted 16.08.2021 \\
\hline Correspondence author \\
Swarup Kumar Kundu \\
Tel.: +8801714871808 \\
E-mail: swarupkundu95@gmail.com \\
\hline 2021 Halder S. et al. This is an \\
open-access article distributed under \\
the terms of the Creative Commons \\
Attribution License, which permits \\
unrestricted use, distribution, and \\
reproduction in any medium, \\
provided the original author and \\
source are credited.
\end{tabular}

(c) EY

Contents

1. Introduction

2. Materias and methods....

3. Results and discussion ........ 46

4. Conclusions ................ 49

References .................... 50

\begin{abstract}
Bacterial disease of poultry is one of the major constraints to the expansion of poultry industry. The study was undertaken to investigate some common bacterial diseases in commercial poultry farm. A total of 100 sick and dead chickens (67 broilers, 26 layers and 7 sonali) were collected from different poultry farms which were subjected to postmortem examination for tentative diagnosis. After the post-mortem examination, out of 100 collected dead chickens, bacterial diseases were confirmed $58 \%$. Among them $52 \%$ of the chickens were diagnosed tentatively to be the case of colibacillosis, $4 \%$ salmonellosis, and $2 \%$ of fowl cholera. In postmortem examination, some pathological lesions like: omphalitis, fibrinopurulent fluid accumulation in peritoneal cavity, air sacculitis, pericarditis and perihepatitis, extreme congestion and septicemia in intestine for colibacillosis infection; unabsorbed yolk mass, bronze discoloration and friable liver, hemorrhages in spleen, misshaped ova for salmonellosis as well as swollen and hardening of comb, congestion of skin, multiple pin point pale color necrotic lesion on liver, pin point hemorrhage on fat muscle of heart were observed for fowl cholera infection. Hence, this study will definitely help to perceive the prevalence of common bacterial diseases like colibacillosis, salmonellosis and fowl cholera infection in commercial poultry farm.
\end{abstract}

Key words: Bacterial diseases, prevalence, gross lesions, poultry farm.

\section{Citation:}

Halder, S., Das, S., Nath, S. K., Kundu, S. K., Islam, M. S., Chowdhury, S., \& Masuduzzaman, M. (2021). Prevalence of some common bacterial diseases in commercial poultry farm. Ukrainian Journal of Veterinary and Agricultural Sciences, 4(2), 44-51.

\section{Introduction}

Poultry industries contributes a remarkable role in Bangladesh economy. Amount of poultry population in Bangladesh is about 304.17 million and duck population is about 48.86 (DLS, 2015). In Bangladesh, maximum people largely depend on agricultural and livestock farming and about $90 \%$ of all rural families engaged in keeping small number of indigenous chicken and duck under free range semiscavenging systems (Das et al., 2008). The most integral part of farming system is poultry sector that has created direct and indirect opportunity for employment facilities, improved food security, contributing country's economic growth and reducing poverty level in both rural and urban areas of Bangladesh (Selim \& Nahid, 2008). Poultry farming offers opportunities for part-time employment particu- larly for village women, children or elderly person on the farm operation (Bangladesh Economic Review, 2011). The requirement for meat and egg products have been increasing dramatically with population growth, income growth, urbanization as well as dietary changes. The contribution of commercial strain of chicken and village poultry was 50:50 in egg production while for meat production it was 60:40 in Bangladesh (Bhuiyan, 2011). The major constraints of village poultry production are enlisted as various diseases, poor husbandry and shortage of feed, all of which hamper the optimal performance of the poultry production in Bangladesh (Haque et al., 1996).

Clinical diagnosis of common bacterial diseases of poultry. The bacterial diseases of poultry encountered commonly in Bangladesh have been reviewed here by put- 
ting emphasis on colibacillosis, salmonellosis and fowl cholera.

Colibacillosis. Avian colibacillosis is caused by Escherichia coli is a member of the family of Enterobacteriaceae, which is considered as an infectious disease of birds causes high morbidity and mortality (Lutful, 2010), along with occurs heavy economic losses to the poultry industry (Yogaratnam, 1995). E. coli infection is one of the major problems reduces the profitability of bird's enterprises all over the world (Bandyopadhay \& Dhawedkar, 1984). Normal inhabitants of $E$. coli is in the intestinal tracts and can also be found in chicken feces, litter, dust and rodent droppings etc (Barnes, 2008). Horizontal dissemination is the most likely method of transmission via the environment, more specifically occurs from other birds, water, faces and feed (Dho-Moulin \& Fairbrother, 1999).

Pullorum disease (Bacillary white diarrhea). Pullorum disease is usually a mainly transmitted to young chicks through the eggs but results in fatal diarrhea within the first four weeks of age and causes severe enteritis and bacteremia (Mozaffor et al., 2010). The etiological agent of fowl typhoid and pullorum disease are denoted as $S$. gallinarum and S. pullorum. Fowl typhoid affecting mostly adult chickens per acute, acute or chronic form of disease, whereas pullorum disease occurs in very young chickens, mostly 2-3 weeks of age. In the adult it appears as chronic (Shivaprashad, 1997; Christensen et al., 1997). Salmonella is transmitted by either horizontal or vertical mode of transmission (Berchieri et al., 2001). A list of risk factors responsible for Salmonella infection of broiler-chicken flocks are given in Table 1.

\section{Table 1}

Factors responsible for Salmonella infection in a broilerchicken flocks

\begin{tabular}{ll}
\hline \multicolumn{1}{c}{ Risk factors } & \multicolumn{1}{c}{ Reference } \\
\hline $\begin{array}{l}\text { Inadequate level of hygiene } \\
\text { Salmonella contamination of the previ- }\end{array}$ & (Henken et al., 1992) \\
ous flock & (Oystein et al., 1996) \\
With a persistence inside the house & (Baggesen et al., 1992) \\
Contaminated day-old chicks and feed & (Oystein et al., 1996) \\
& (Davies et al., 1997) \\
The farm structure ( $>3$ houses on the & (Oystein et al., 1996) \\
farm) & (Oystein et al., 1996) \\
Wet and cold season & (Baggesen et al., 1992) \\
Litter-beetle infestation of the house
\end{tabular}

Fowl cholera. Fowl cholera is caused by Pasteurella multocida and recognized as a highly contagious disease that attacks a broad host range of birds and cause high mortality that significant economic losses in poultry production (Bisgaard et al., 2003). Fowl Cholera can affect the birds of any age, but it rarely occurs less than 8 weeks of age in commercial poultry (Rimler, 1994) and survive for at least, 2 to 3 months in soil and 1 month in droppings. The organism can enter the body via the respiratory system or digestive tract. The disease cannot be transmitted via the egg. The primary source of P. multocida excreted from the nostrils, eyes and mouth of sick or chronic birds. The secondary sources are contaminated feed, water, equipment and shoes. Wild birds, including pigeons and sparrows along with many mammals (especially pigs, cats, and wild rodents) can also disseminate P. multocida (Onet \& Shivaprasad, 1995).
Sign and symptoms. Common and highly occurring bacterial diseases of poultry in Bangladesh are colibacillosis pullorum disease (PD) and fowl cholera (FC) which are responsible for rising the percentage rate of morbidity and mortality in a flock (Samad, 2000). Avian colibacillosis is an infectious disease of birds cause many clinical manifestations such as pericarditis, airsacculitis, septicemia, and death of the birds. Salmonellosis is another important bacterial diseases in poultry causing huge economic losses by increasing mortality rate and decreasing meat and egg production (Haider et al., 2004). The incidence of salmonellosis in Bangladesh was found to be $9.28 \%$ (Bhattacharjee et al., 1996). Increased mortality, sudden drop in egg production, anorexia and white or yellow diarrhea are the characteristic clinical signs of the diseases. The gross lesions in chicks are turbid yellow color fluids and unabsorbed yolk sac in the peritoneal cavity and in adult peritonitis, small white necrotic foci in the liver with or without enteritis, salpingitis, peritonitis, and perihepatitis (Shivaprasad, 2000). Fowl cholera is a contagious bacterial disease of poultry and identified as a major threat for poultry production which hamper the profitability in poultry industry (OIE, 2008). Respiratory tract infection in poultry are mainly caused by $P$. multocida (Bisgaard et al., 2003) which also found in cloacal mucosa of asymptomatic birds and these strain remain as the sources of outbreaks (Muhairwa et al., 2000). The clinical signs of fowl cholera are fever, anorexia, ruffled feathers, discharge from mouth, mucus, rapid respiration and diarrhea which is watery to yellowish initially and greenish with mucus finally (Rhoades \& Rimler, 1990). Commonly observed lesions are focal necrotic area with swollen liver and hemorrhage at the base of the heart, peritoneal fluids and increased pericardial (Calnek et al., 1997). Therefore, the objective of the present research is to focus the prevalence rate of common bacterial diseases in poultry farm that might be confirmed on the basis of necropsy examination.

\section{Materials and methods}

Study period, place and population. The study was conducted over 6 months' of time from February to July 2018 at the Department of Pathology and Parasitology, Faculty of Veterinary Medicine, Chattogram Veterinary and Animal Science University (CVASU), Chattogram. A total of 100 dead and sick chickens from various farms of Chattogram, Bangladesh were collected and tested at pathology laboratory, CVASU, Chattogram.

Postmortem examination. Postmortem of the sick and dead birds and diagnosis of the disease were performed by expert technical hands by following standard and systematic way in the Department of Pathology and Parasitology, CVASU. Liver, lung, heart, spleen, proventiculus, intestine and caeca were examined carefully and findings were recorded. After that samples (liver, heart) were collected in separated zipper bags from sick and dead birds that were suspected positive by postmortem examination. It was done under aseptic condition to avoid any chance of contamination.

Questionnaire for overall assessment. A standard questionnaire was designed to collect the objectives oriented data via interviewing the farmers and observing the record books. The postmortem findings were recorded that thought to be useful for the diagnosis of avian salmonellosis, colibacillosis, and fowl cholera in poultry chickens. Questionnaire briefly included the following information: 
- Serial number

- Date of data collection

- Name of farm

- Contact details

- Types of bird, age of birds, total number of birds

- $\quad$ Rearing and feeding system

- $\quad$ Source of drinking water

- Medication status

- Vaccination status

- Clinical sign

- $\quad$ Postmortem findings with diagnosis

Statically analysis. Data were entered into a database (Spreadsheet of Microsoft Excel) and was analyzed with $\mathrm{P}$ value by using Graph Pad Software.

\section{Results and discussion}

\section{Results}

Tentative diagnosis of bacterial diseases on the basis of postmortem examination. Based on tentative diagnosis, bacterial diseases were found $58 \%$. Among them $52 \%$ of the chickens were diagnosed tentatively to be the case of colibacillosis, $4 \%$ to be the case of salmonellosis, and $2 \%$ to be the case of fowl cholera. The graphical presentation of the result is shown in Fig. 1. The highest numbers of birds were bought from Rawjan upazila $(21 \%)$ whereas lowest number of birds from Lohagara upazilla (3\%) (Fig. 2). Upazilla wise disease findings are shown in Fig. 3.

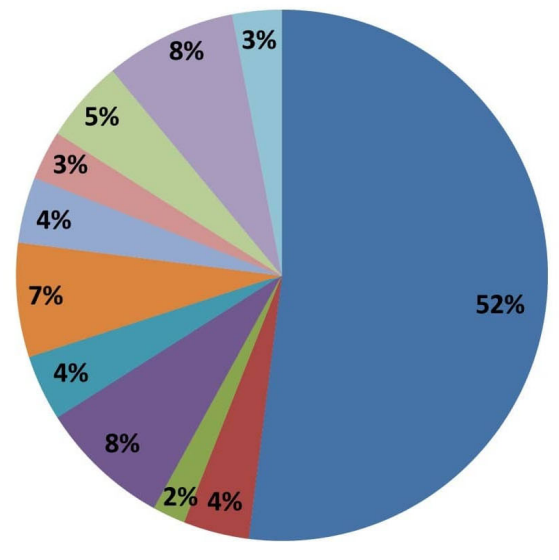

\author{
- Colibacillosis \\ - Salmonellosis \\ Fowl cholera \\ Mycoplasmal infection \\ - Vitamin deficiency \\ - Protozoal diseases \\ Parasitic diseases \\ Managemental problem \\ Fungal infection \\ - Viral diseases \\ Mixed infection
}

Fig. 1. Frequency of different poultry diseases diagnosed tentatively on the basis of clinical signs and postmortem lesions

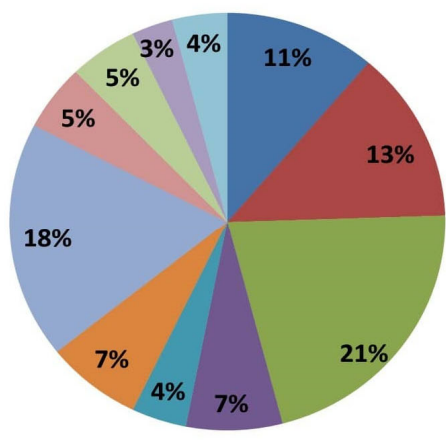
- Chattogram

$\square$ Patiya
$\square$ Rawjan
$\square$ Anowara
$\square$ Hatazari
$\square$ Sitakundu
$\square$ Boalkhali
$\square$ Chandanaish
$\square$ Fotikchori
$\square$ Lohagara
$\square$ Banskhali

Fig. 2. Percentage of birds came from different study region of Chattogram district

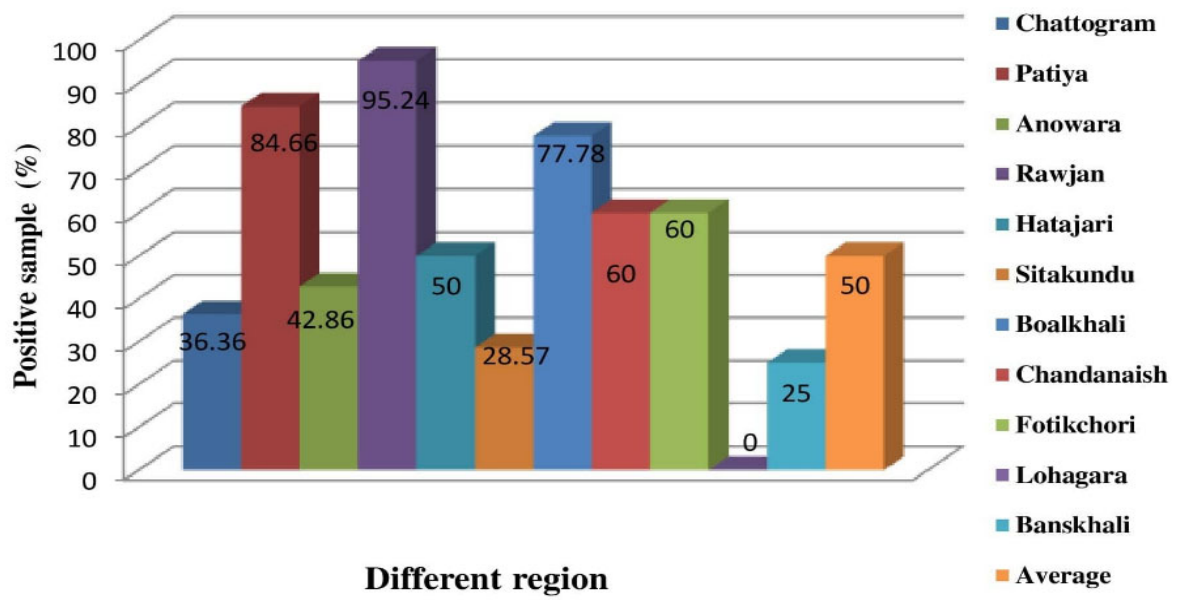

Fig. 3. Occurrence of colibacillosis and salmonellosis in different region of Chattogram 
Prevalence of common bacterial diseases on the basis of different factors. Out of 100 chickens, Colibacillosis was found in $52 \%$ birds. Out of 100 chickens, Salmonellosis was found in $4 \%$ birds. Out of 26 layer birds, Fowl chol- era was found in $2 \%$ birds. The percentage of Colibacillosis, Salmonellosis and Fowl cholera varied proportionally according to age, litter, and farm size, source of water, source of food, medication and vaccination (Table 2).

Table 2

Association of different variables with samples positive in Direct Microscopic Examination

\begin{tabular}{|c|c|c|c|c|c|}
\hline Variables & Category/level & $\begin{array}{l}\text { Number of } \\
\text { observation }\end{array}$ & $\begin{array}{c}\text { Number of } \\
\text { positive }\end{array}$ & Percentage $(\%)$ & $\begin{array}{c}\text { P-value } \\
\text { (Chi-square test }\end{array}$ \\
\hline \multirow[t]{2}{*}{ Production type } & Layer & 26 & 2 & 8 & \multirow[t]{2}{*}{-} \\
\hline & $0-\leq 2$ & 0 & 0 & 0 & \\
\hline \multirow[t]{3}{*}{ Age (week) } & $>2-\leq 4$ & 0 & 0 & 0 & \multirow[t]{3}{*}{-} \\
\hline & $>4$ & 26 & 2 & 8 & \\
\hline & 500-1000 (small) & 2 & 0 & 0 & \\
\hline \multirow[t]{2}{*}{ Farm size } & 1001-2000 (medium) & 5 & 1 & 20 & \multirow{2}{*}{0.038} \\
\hline & >2000 (large) & 19 & 1 & 5 & \\
\hline \multirow{2}{*}{$\begin{array}{l}\text { Bird rearing } \\
\text { system }\end{array}$} & Cage & 20 & 2 & 10 & \multirow[b]{2}{*}{-} \\
\hline & Litter & 6 & 0 & 0 & \\
\hline \multirow{2}{*}{ Type of feed } & Handmade & 13 & 2 & 15 & \multirow[b]{2}{*}{-} \\
\hline & Readymade & 13 & 0 & 0 & \\
\hline \multirow{2}{*}{ Source of water } & Tube well & 17 & 2 & 12 & \multirow{2}{*}{0.23} \\
\hline & WASA & 9 & 0 & 0 & \\
\hline \multirow{2}{*}{$\begin{array}{l}\text { Previous treat- } \\
\text { ment }\end{array}$} & Yes & 18 & 2 & 11 & \multirow[b]{2}{*}{-} \\
\hline & No & 8 & 0 & 0 & \\
\hline \multirow{2}{*}{ Vaccination } & Yes & 21 & 1 & 4 & \multirow{2}{*}{0.06} \\
\hline & No & 5 & 1 & 20 & \\
\hline
\end{tabular}

Gross study. During the post-mortem examination, some gross lesions like omphalitis, fibrinopurulent fluid accumulation in peritoneal cavity, air sacculitis, pericarditis and perihepatitis, extreme congestion and septicemia in intestine for colibacillosis (Fig. 4); unabsorbed yolk mass, bronze discoloration and friable liver, hemorrhages in spleen, misshaped ova for salmonellosis (Fig. 5); as well as as swollen and hardening of comb, congestion of skin, multiple pin point pale color necrotic lesion on liver, pin point hemorrhage on fat muscle of heart were found for fowl cholera (Fig. 6) infection.

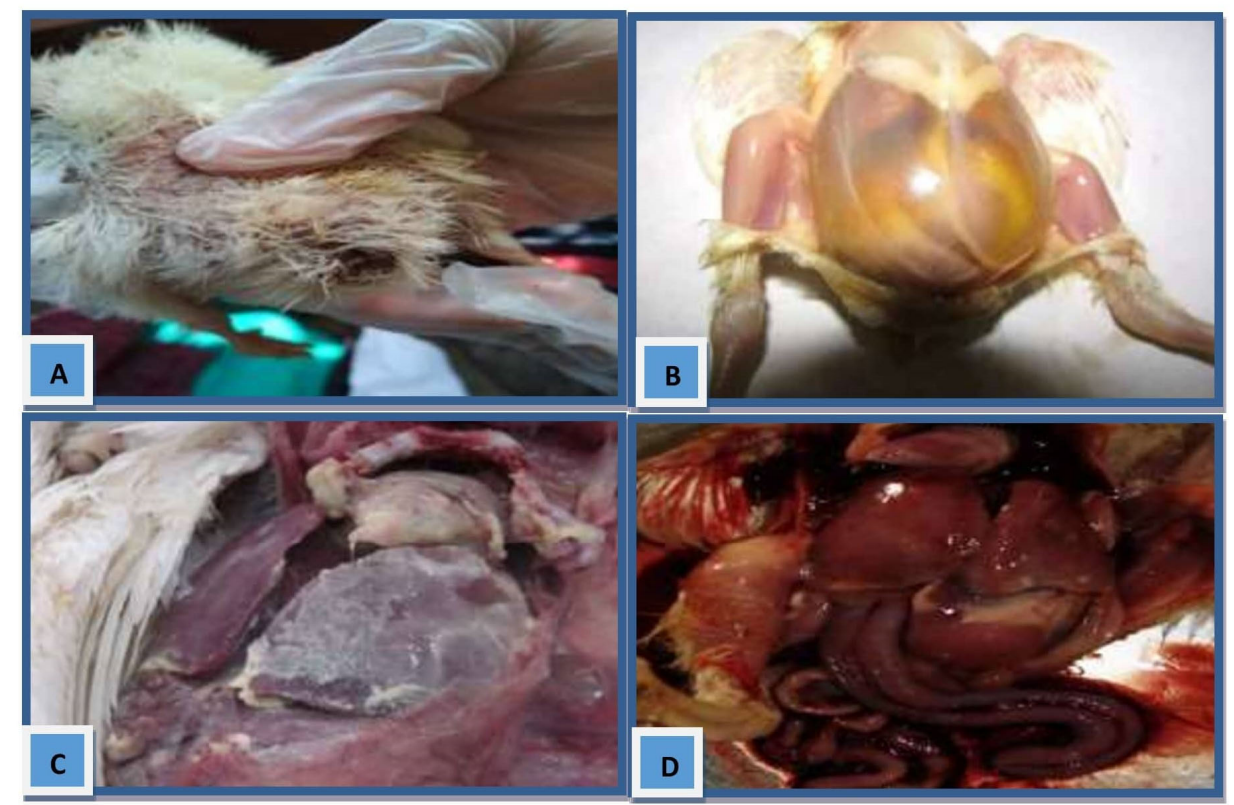

Fig. 4. Gross lesions found in chickens in case of colibacillosis. A: Omphalitis B: Fibrinopurolent fluid accumution in peritoneal cavity $\mathrm{C}$ : Airsacculitis, pericarditis and perihepatitis D: Extreme congestion and septicemia in intestine 


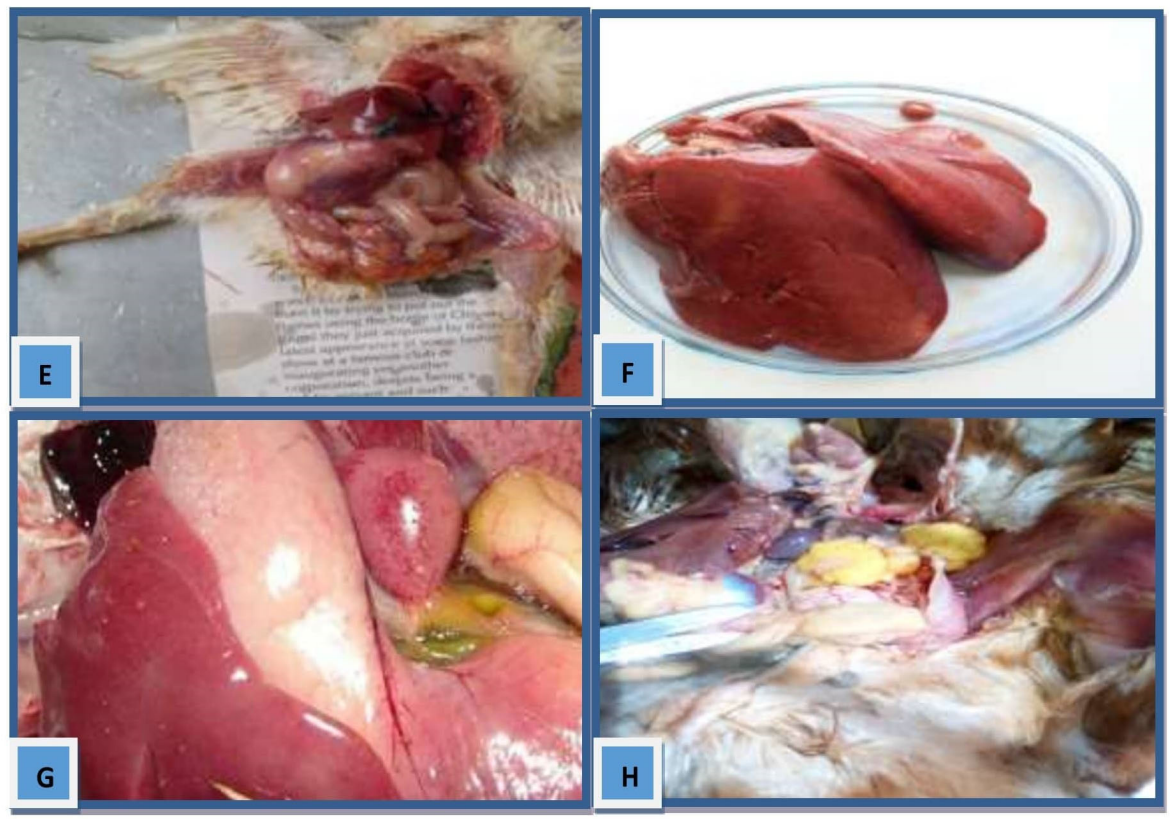

Fig. 5. Gross lesions found in chickens in case of salmonellosis. E: Unabsorbed yolk mass F: Bronze discoloration and friable liver G: Haemorrhages in spleen H: Haemorrhagic, misshapened and pedunculated ova

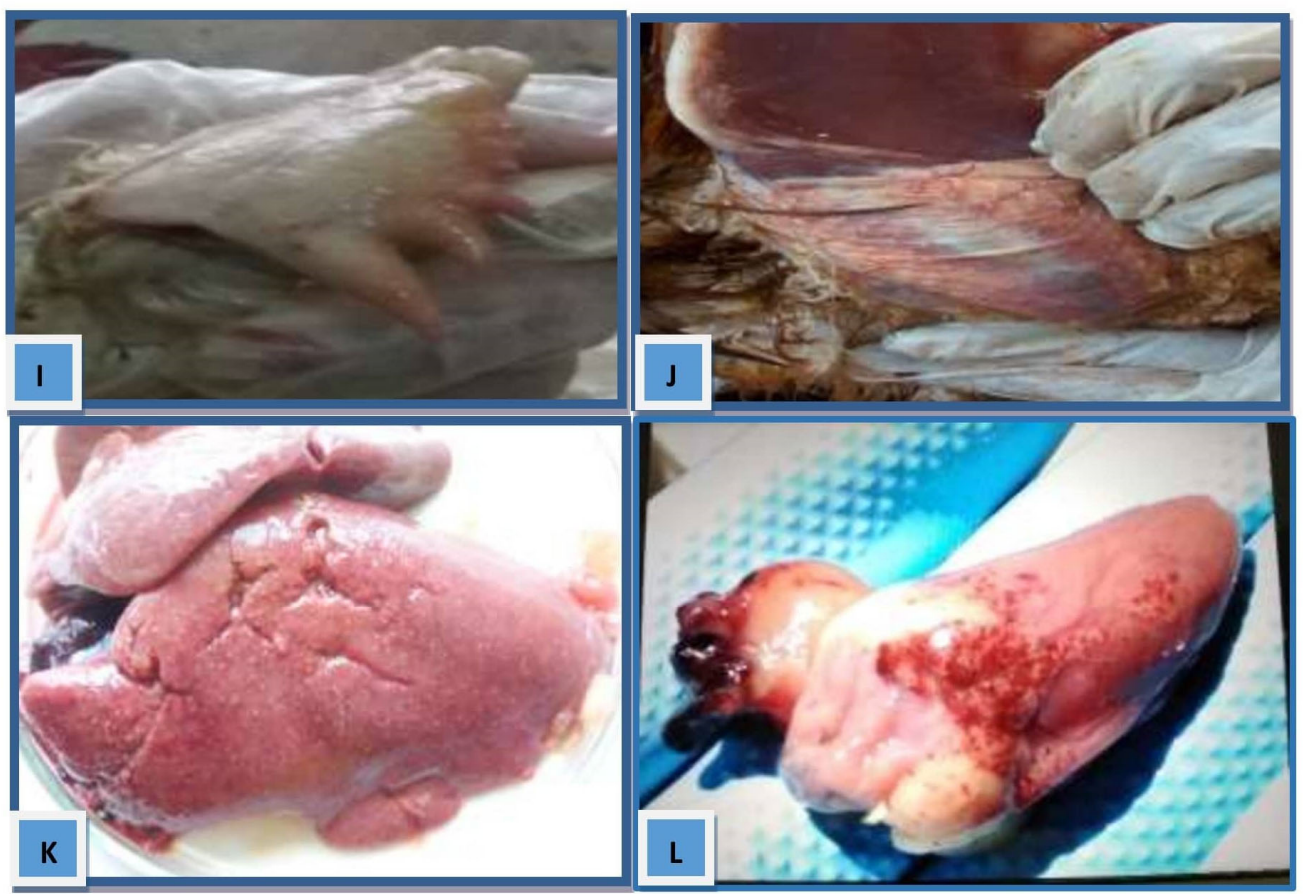

Fig 6. Gross lesions found in chickens in case of fowl cholera. I: Swollen and hardening of comb J: General congestion of skin $\mathrm{K}$ : Multiple pin point pale color necrotic lesion on overall liver L: Pin point hemorrhage on fat muscle of heart

\section{Discussion}

Bacterial diseases most commonly occur in chickens of all group of age. The overall prevalence of bacterial diseases was about $52 \%$ in the commercial chickens in Chattogram region. A total of 100 chickens of various farms were diagnosis through post-mortem examination and among them $52 \%$ chickens were diagnosed with colibacillosis and $4 \%$ chickens were diagnosed with salmonellosis. Out of 26 layers, $2 \%$ chickens were diagnosed with fowl cholera.

Prevalence of common bacterial diseases (colibacillosis, salmonellosis and fowl cholera) in chickens. According to clinical signs and postmortem lesions $52 \%$ of the chickens were diagnosed tentatively with colibacillosis. This finding is close but slightly higher than the findings of Ahmed et al. (2009) and Hashem et al. (2012) which were
$52.26 \%$ and $54.55 \%$, respectively. Hossain et al. (2013) found slightly lower infection rate $(30.43 \%)$ than our finding. On the contrary, Giasuddin et al. (2002), Islam et al. (2003) and Uddin et al. (2010) recorded the disease at a very lower rate which was $4.42 \%, 5.17 \%$ and $5.70 \%$, respectively. Rahman et al. (2004) however, recorded the disease at a level of $21.09 \%$ (147out of 697 birds). But during culture the findings were $48 \%$ which is higher than the findings of Hasan et al. (2010) who found $32 \%$ colibacillosis in commercial chickens. According to post mortem diagnosis and clinical sign, the prevalence of salmonellosis was found $7 \%$ in layer chickens. These results support the earlier reports of Giasuddin et al. (2002) reported $5.56 \%$, Islam et al. (2003) reported $6.73 \%$ and Biswas et al. (2005) reported $7.09 \%$. This difference may be due to the number of sam- 
ples, method used for the isolation, presence of stress and age of birds sampled etc. However, on the basis of cultural properties the prevalence of salmonellosis was found at the rate of $5 \%$ which was 3 times lower than the result of Hasan et al. (2010) who found $13.64 \%$ positive in their study. But during culture the findings were $5 \%$ which is lower than the findings of Hasan et al. (2010) who found $20 \%$ salmonellosis in commercial chickens. In our study, the prevalence of fowl cholera were found $4 \%$ which is quite similar to the findings of Giasuddin et al. (2002), Islam et al. (2003) which is $3.08 \%$ and $0.44 \%$ respectively, but the findings is much lower than the findings of Biswas et al. (2005) and Rahman et al. (2004) which is $6.76 \%$ and $16.35 \%$ respectively. Hasan et al. (2010) reported $12.50 \%$ which was higher than this study. Islam et al. (2003) found $0.44 \%$ and Uddin et al. (2010) found $0.24 \%$ Fowl cholera in commercial layer which was lower than this study. But during laboratory diagnosis the findings were $8 \%$ which is lower than the findings of Hasan et al. (2010) who found $12.5 \%$ fowl cholera in commercial layer chickens.

Risk factor associated common bacterial diseases (colibacillosis, salmonellosis and fowl cholera) in chickens. Association of bacterial infection with production type, litter type and age, farm size source of water type of feed were evaluated. But we failed to find any paper comparing the prevalence of colibacillosis in relation to some of these factors; therefore we could not compare our findings with other works of similar nature. In case of production type prevalence was higher $(57 \%)$ in sonali than commercial layer $(46 \%)$ and commercial broiler (47 \%). However, Islam et al. (2012) did not find any significant difference in the occurrence of bacterial diseases in broiler $(28.6 \%)$ and layer $(27.6 \%)$ birds. Prevalence of bacterial diseases varied among different age group of birds and the highest (60\%) was found in $0-\leq 2$ weeks age groups with the lowest (43\%) being in $>4$ weeks age group of birds. Islam et al. (2003) also reported in general, the highest number poultry diseases to occur in the age group of 8-21 days $(42.60 \%)$, followed by $22-35$ days age group (26.62\%), 0-7 days age group $(26.10 \%), 36-60$ days age group $(1.03 \%)$ and over 60 days age group (3.62\%) of Poultry. Similarly, according to Uddin et al. (2010) the highest number of cases were recorded in the age group of 8-20 days which was $42.64 \%$, followed by $35.76 \%$ in $21-3$ days age group, $16.12 \%$ in $0-7$ days age group, $1.52 \%$ in 36-60 days age group and $3.96 \%$ in $>60$ days age group of poultry. Prevalence of salmonellosis varied among different age groups, highest (11\%) prevalence was found in $>4$ weeks age groups and lowest $(0 \%)$ in age group $0-\leq 2$ weeks. These findings relating to age of birds correlate with the finding of Mahmud et al. (2011), who reported the disease to occur 30-35 weeks onward in chicken and also relating with the finding of Hossain et al., (2010), who reported the disease was recorded the highest in adult compared to young. Occurrence of salmonellosis was found to be highest in handmade feed supply (8\%) and $(5 \%)$ were positive to salmonellosis in case of readymade feed supply and the relationship was statistically significant $(\mathrm{P}<0.05)$. Occurrence of fowl cholera was highest $(20 \%)$ in medium sized farms followed by large $(10 \%)$ and small ( $0 \%)$ sized farm. According to the collected data, the highest frequency of positivity of fowl cholera was found at the age of more than four weeks $(8 \%)$ and the lowest was found at the age of less than four weeks $(0 \%)$. Prevalence was higher in cage rearing system $(10 \%)$, non-vaccinated bird
(20\%), birds with previous treatment $(11 \%)$ and birds with handmade feed supply (15\%).

Pathological study of common bacterial diseases (colibacillosis, salmonellosis and fowl cholera) in chickens. In this study efforts had been made to identify different forms (gross lesions) of colibacillosis by postmortem. Those forms were air sacculitis, omphalitis, pericarditis, perihepatitis septicaemia, enteritis, peritonitis and a combination of different forms at a time. These forms of colibacillosis were already mentioned by different authors (Pourbakhsh et al., 1997; Shah et al., 2003; Rahman et al., 2004; Khaton et al., 2008; Chowdhury et al., 2009). The microscopic lesion in liver showed congestion, necrotic lesions, infiltration of heterophils, lymphocytes and macrophages surrounding the portal veins, fibrosis of the capsule, dilated blood vessels. Pericarditis was characterized by thickening of pericardium due to infiltration of RE cells. Similar lesions have been reported by Nakamura et al. (1985), Khaton et al. (2008), El-Ghany and Madian (2011), Myers et al. (2012). The gross lesions of salmonellosis observed in our study were bronze coloration of liver associated with fatty change, hemorrhages in spleen, unabsorbed yolk in chicks, hemorrhagic and misshaped ova from layer birds. The findings are relevant to the findings of Kumari et al. (2013) and Shivaprashad et al. (2013). According to Saha et al. (2012), livers of Salmonella spp. affected birds were enlarged, congested, friable and bronze colored with white necrotic foci. Wray et al. (1996) found as postmortem findings were misshaped, discolored, pedunculated, cystic ova with various forms of pericarditis and peritonitis. In the present study all of these changes were found as postmortem findings of Salmonella spp. affected birds. Histopathological changes found in chickens during this study were congestion, coagulation necrosis of liver, fatty changes in liver, infiltration of reactive cells, congested central vein and capillaries, centrilobular congestion and diffuse necrosis which were almost similar to the findings of Rahman et al. (2011), Saha et al., (2012) and Kumari et al. (2013). In the present study, gross findings of FC in chickens including congested body, cyanotic, swollen and hardening of comb, cloudy air sacs, congested pneumonic lungs with adhesion, congested and enlarged liver with friable texture and pin point grayish white necrotic foci, fibrinous perihepatitis, peritonitis, pericarditis with congested or hemorrhagic coronary fat, congested kidneys, enlarged congested spleen were in agreement with previous literatures reported by Arshed et al. (2003), Silpa et al. (2006), Mohamed et al. (2012).

\section{Conclusions}

Most of the people in our country basically depends on agricultural sector. Many people invest a huge amounts in poultry sector as an entrepreneur. But they have a lack of knowledge about the poultry rearing. Most of them have no knowledge about the diseases, rearing system, disease prevalence of poultry. Due to the lack of knowledge about common poultry diseases in a farm they cannot get their desired profit. Present research might be focus the prevalence and pathological lesions of common bacterial diseases (avian colibacillosis, salmonellosis and fowl cholera) in commercial poultry farm to the people by which they can easily aware of that from the very beginning of the rearing of poultry as well as they can take necessary action in case 
of the prevalence of that common bacterial diseases in their farm.

\section{Acknowledgements}

We are grateful to all personnel involved in this research study for their valuable time, opinion, advice, and suggestions. The author would like to thank the Department of Pathology and Parasitology, Chattogram Veterinary and Animal Sciences University, for their technical support.

\section{Conflict of interest}

The authors declare that there is no conflict of interest.

\section{References}

Ahmed, M. S., Sarker, A., \& Rahman, M. M. (2009). Prevalence of infectious diseases of broiler chickens in Gazipur district. Bangladesh Journal of Veterinary Medicine, 7(2), 3326-3331. doi: 10.3329/bjvm.v7i2.5999.

Arshed, M. J., Siddique, M., \& Sajjad, U. R. (2003). Preliminary studies on Fowl Cholera in Layers. Pakistan Journal of Life and Social Sciences, 1, 34-36.

Awadin, W., Ghaly, S., \& Elsawak, A. (2017). Pathological and Immunohistochemical Study of P. multocida Capsular Type A in Tissue of Chickens and Ducks Infected with Fowl Cholera. Assiut Veterinary Medical Journal, 63(153), 1-18. doi: 10.21608/avmj.2017.166597.

Baggesen, D. L., Olsen, J. E., \& Bisgaard, M. (1992). Plasmid profiles and phages types of Salmonella typhimurium isolated from successive flocks of chickens on three parent stock farms. Avian Pathology, 21(4), 569-579. doi: 10.1080/03079459208418878.

Bandyopadhay, P. K., \& Dhawedkar, R. G. (1984). E. coli salpingoperitonitis in poultry. Indian Veterinary Journal, 61, 348-349.

Bangladesh Economic Review (BER). (2011). E. N. Ministry of finance.

Barnes, J. (2008). Diseases of poultry. 12th ed. Blackwell publ. Ames. I. A. 706-707.

Berchieri, A., Murphy, Jr., Marston, C. K., \& Barrow, P. A. (2001). Observations on the persistence and vertical transmission of Salmonella enteric serovars Pullorum and S. gallinarum in chickens: effect of bacterial and host genetic background. Avian Pathology, 30(3), 221-231. doi: 10.1080/03079450120054631.

Bhattacharjee, P. S., Kundu, R. L., Biswas, R. K., Mazumder, J. U., Hossain, E., \& Miah, A. H. (1996). A retrospective analysis of chicken diseases diagnosed at the central disease investigation laboratory, Dhaka. Bangladesh veterinary journal, 30, 105-113.

Bhuiyan, A. K. F. H. (2011). Implementation of national livestock development policy (2007) and national poultry development policy (2008): Impact on smallholder livestock rearers. Keynote paper presented at the South Asia Pro Poor Livestock Policy Programme (SAPPLP)-BARC workshop held at BRAC Centre Inn, Dhaka.

Bisgaard, M. H., Christensen, A. M., Bojese, \& Christensen, J. P. (2003). Avian infections caused by species of Pasteurellaceae.

Biswas, P. K., Biswas, D., Ahmed, S., Rahman, A., \& Debnath, N. C. (2005). A longitudinal study of the incidence of major endemic and epidemic diseases affecting semi-scavenging chickens reared under the participatory livestock development project areas in Bangladesh. Avian Pathology, 34(4), 303-312. doi: 10.1080/03079450500178972.

Calnek, B. W., Barnes, H. J., Beard, C. W., Mcdougald, L. R., \& Saif, Y. M. (1997). Diseases of poultry, 10thed, Iowa state university press, Ames, IA, USA

Chowdhury, S., Masuduzzaman, M., \& Shatu, S. N. (2009). A pathological investigation to identify different forms of Colibacillosis in commercial broiler and layer birds in Chattogram region. Eco-friendly Agricultural Journal, 2, 368-373.

Christensen, J. P., Brown, D. J., Madsen, M., Olsen, J. E., \& Bisgaard, M. (1997). Hatchery-borne Salmonella enteric serovar tennessee infections in broilers. Avian Pathology, 26(1), 155168. doi: 10.1080/03079459708419202.

Christiansen, H., \& Bisgaard, M. (2003). The genus Pasteurella. In: The prokaryotes: an evolving electronic resource for the microbiological community, Ver. 3, 13, 1062-1090.

Das, S. C., Chowdhury, S. D., Khatun, M. A., Nishibori, M., Isobe, N., \& Yoshimura, Y. (2008). Poutry Production Profile and Expected Future Projection in Bangladesh. World's poultry science journal, 64(01), 99-118. doi: 10.1017/S0043933907001754.

Davies, R. H., Nicholas, R. A. J., Mclaren, I. M., Corkish, J. D., Lanning, D. G., \& Wray, C. (1997). Bacteriological and serological investigation of persistent Salmonella enteritidis infection in an integrated poultry organisation. Veterinary Microbiology, 58(2-4), 277-293. doi: 10.1016/S0378-1135(97)00157-0.

Dho-Moulin, M., \& Fairbrother, J. M. (1999). Avian pathogenic Escherichia coli (APEC). Veterinary Research, 30(2-3), 299316. URL: https://pubmed.ncbi.nlm.nih.gov/10367360.

DLS (2015). Annual report on livestock. Division of Livestock Statistics, Ministry of Fisheries and Livestock, Farmgate, Dhaka, Bangladesh.

El-Ghany, W. A. A., \& Madian, K. (2011). Control of experimental colisepticaemia in broiler chickens using sarafloxacin. Life Science Journal, 8(3), 318-328.

Giasuddin, M., Sil, B., Alam, J., Koike, I., Islam, M. R., \& Rahman, M. M. (2002). Prevalence of poultry diseases in Bangladesh. Journal of Biological Sciences, 2(4), 212-213. doi: $10.3923 /$ jbs.2002.212.213.

Haider, M. G., Hossain, M. G., Hossain, M. S., Chowdhury, E. H., Das, P. M., \& Hossain, M. M. (2004). Isolation and characterization of Enterobacteria associated with health and disease in Sonali Chickens. Bangladesh Journal of Veterinary Medicine, 2(1), 15-21. doi: 10.3329/bjvm.v2i1.1928.

Haque, M. M., Biswas, H. R., \& Rahman, L. (1996). Isolation, identification and production of Salmonella pullorum colored antigen in Bangladesh for the rapid whole blood test. AsianAustralasian Journal of Animal Sciences, 10(1), 141-146. doi: 10.5713/ajas.1997.141.

Hasan, R. M. K. A., Ali, M. H., Siddique, M. P., Rahman, M. M., \& Islam, M. A. (2010). Clinical and laboratory diagnosis of New castle and Infectious bursal diseases of Chickens. Bangladesh Journal of Veterinary Medicine, 8(2), 131-140. doi: 10.3329/bjvm.v8i2.11196.

Hashem, M. A., Elahi, M. F., Mannan, M. A., Mannan, M. F., Kabir, M. H. B., Kashem, M. A., \& Pallab, M. S. (2012). Isolation, identification and antibiogram of Escherichia coli from broiler at Chattogram district Bangladesh. Wayama Journal of Animal Science, 2012-578x, 312-316. URL: https://wayambajournal.com/paper/isolation-identification-andantibiogram-of-eschericia-coli-from-broiler-at-chittagongdistrict-in.pdf.

Henken, A. M., Frankena, K., Goelema, J. O., Graat, E. A. M., \& Noordhuizen, J. P. T. M. (1992). Multivariate epidemiological approach to salmonellosis in broiler breeder flocks. Poultry Science Journal, 71(5), 838-843. doi: 10.3382/ps.0710838.

Hossain, M. S., Akter, S., Ali, M., Das, P. M., \& Hossain, M. M. (2013). Bacteriological and pathological investigation of nasal passage infections of chickens. Science Journal of Krishi Found, 11(1), 47-55. doi: 10.3329/agric.v11i1.15241.

Islam, A., Majumder, S., Rahman, A., Trisha, A. A., \& Amin, R. (2012). Retrospective study of commercial poultry diseases. Eurasian Journal of Veterinary Sciences, 28, 116-121.

Islam, M. N., Huque, Q. M. E., Uddin, M. S., \& Sarker, M. S. K. (2003). Potentiality of native genotypes of ducks. In: Proceedings of the 3rd International Poultry Show and Seminar, Dhaka, Bangladesh, The World's Poultry Science Association, Bangladesh Branch, 259-270.

Khaton, R., Haider, M. G., Paul, P. K., Das, P. M., \& Hossain, M. M. (2008). Colibacillosis in commercial chickens in Bangladesh. Bangladesh Veterinarian, 25(1), 17-24. doi: 10.3329/bvet.v25i1.4614. 
Kumari, D., Mishra, S. K., \& Lather D. (2013). Pathomicrobial studies on Salmonella gallinarum infection in broiler chickens. Veterinary world, 6, 725-729. doi: 10.14202/vetworld.2013.725-729.

Luna, L. G. (1968). Manual of histologic staining methods of the armed forces institute of pathology, 3rd ed. McGraw Hill Book Co. New York, USA, 1-32.

Lutful, K. S. M. (2010). Avian Colibacillosis and Salmonellosis. In: A closer look at epidemiology, pathogenesis, diagnosis, control and public health concerns. International Journal of Environmental Research and Public Health, 7(1), 89-114. doi: 10.3390/ijerph7010089.

Mahmud, S. M., Bari, L. M., \& Hossain, A. M. (2011). Prevalence of Salmonella serovars and antimicrobial resistance profiles in poultry of savar Area, Bangladesh. Food borne pathogens and diseases, 8(10), 1111-1118, doi: 10.1089/fpd.2011.0917.

Mohamed, M. A., Mohamed, M. W., Ahmed, I. A., Ibrahim, A. A., \& Ahmed, M. S. (2012). Pasteurella multocida in backyard chickens in Upper Egypt: incidence with polymerase chain reaction analysis for capsule type, virulence in chicken embryos and antimicrobial resistance. Veterinaria italiana, 48(1), 7786. URL: https://pubmed.ncbi.nlm.nih.gov/22485004.

Mozaffor, K. M., Hossain, M., Hossain, T., \& Yamato, I. (2010). Seroprevalence of Salmonella and Mycoplasma gallisepticum infection in chickens in Rajshahi and surrounding districts of Bangladesh. International Journal of Biology, 2(2), 74-80. doi: 10.5539/ijb.v2n2p74.

Muhairwa, A. P., Christensen, A. P., \& Bisgaard, M. (2000). Investigations on the carrier rate of P. multocida in healthy commercial poultry flocks and flocks affected by fowl cholera. Avian Pathology, 29(2), 133-142. doi: 10.1080/03079450094162.

Myers, R. K., McGavin, M. D., \& Zachary, J. F. (2012). Cellular Adaptations, Injury and Death: Morphological, biochemical and genetic bases. In: Pathological Basis of Veterinary Diseases. (Zachary J. F., McGavin M. D., editors). 1st edition. Elsevier Mosby, St. Louis, Missouri, USA, 1-59.

Nakamura, K., Maeda, M., Imada, Y., Imada, T., \& Sato, K. (1985). Pathology of Spontaneous Colibacillosis in a Broiler Flock. Veterinary Pathology, 22(6), 592-597. doi: $10.1177 / 030098588502200614$.

OIE (2008). Manual of standards for diagnostic test and vaccines.

Onet, G. E., \& Shivaprasad, H. L. (1995). Fowl Cholera. AAAP Slide study set \# 19. American Association of Avian Pathologists, INC. 1-12. URL: https://www.aaap.info/assets/ Slides/fowl_cholera_19_1995.pdf.

Oystein, A., Skov, M. N., Chriel, M., Agger, J. F., \& Bisgaard, M. (1996). A retrospective study on Salmonella sp. infection in Danish broiler flocks. Preventive Veterinary Medicine, 26(3-4), 223-237. doi: 10.1016/0167-5877(95)00549-8.

Pourbakhsh, S. A., Boulianne, M., Martineau-Doizé, B., Dozois, C. M., Desautels, C., \& Fairbrother J. M. (1997). Dynamics of Escherichia coli infection in experimentally inoculated chickens. Avian Diseases, 41(1), 221-233. doi: 10.2307/1592463.

Rahman, M. A., Samad, M. A., Rahman, M. B., \& Kabir, S. M. L. (2004). Bacterio-pathological studies on Salmonellosis, Coli- bacillosis and Pasteurellosis in Natural and Experimental Infections in Chickens. Bangladesh Journal of Veterinary Medicine, 2(1), 01-08. doi: 10.3329/bjvm.v2i1.1926.

Rahman, M. R., Shahinuzzaman, A. B. M., Saha, A. K., Sufian, M. A., Rahman, M. H., \& Hossain, M. M. (2011). Prevalence of Salmonella infection in naturally infected layer birds in Bangladesh. The Bangladesh Veterinarian, 28, 8-18. doi: 10.3329/BVET.V28I1.8809.

Rhoades, K. R., \& Rimler, R. B. (1990). P. multocida colonization and invasion in experimentally exposed turkey poults. Avian. Disease, 34(2), 381-383. URL: https://pubmed.ncbi.nlm.nih.gov/2369377.

Rimler, R. B. (1994). Presumptive identification of Pasteurella multocida serogroups $\mathrm{A}, \mathrm{D}$, and $\mathrm{F}$ by capsule depolymerisation with mucopolysaccharidases. Veterinary Record, 134(8), 191192. doi: $10.1136 / \mathrm{vr} .134 .8 .191$

Saha, K. A., Sufian, M. A., Hossain, M. I., \& Hossain, M. M. (2012). Salmonellosis in layer chickens: Pathological features and isolation of bacteria from ovaries and inner content of laid eggs. Journal of the Bangladesh Agricultural University, 10(1), 61-67. URL: https://www.banglajol.info/index.php/JBAU/article/view/ 12095.

Samad, M. A. (2000). An overview of livestock research reports published during the 20th century in Bangladesh. Bangladesh Veterinary Journal, 34, 53-149.

Selim, R., \& Nahid, M. (2008). Trade and Poverty Linkages In: A Case Study of the Poultry Industry in Bangladesh. CUTS International, 1-9. ISBN: 978-81-8257-112-9.

Shah, Q. A., Soomro, N. M., \& Tunio, S. N. (2003). Colibacillosis in Broiler: Prevalence and Pathology. One line Journal of Biological Science, 3, 287-290.

Shilpa, S., Verma, P. C., \& Minkshi, D. (2006). Pathology of P. multocida infection in chickens. International Journal of Animal Research, 40, 15-19.

Shivaprasad, H. L. (2000). Fowl typhoid and pullorum disease. Rev. Sci. Tech., 19, 405-424.

Shivaprashad, H. L. (1997). Pullorum disease and fowl typhoid. In: Diseases of Poultry, 10th ed., Calnek B. W., Barnes H. J., Beard C. W., McDoughald L. R., Saif Y. M., Eds., Iowa State University press, Ames IA., USA, 82-96.

Shivaprashad, H. L., Methner, U., \& Barrow, P. A. (2013). Salmonella infections in the domestics fowl. In: Methner U. and Barrow P. A. 2013. Salmonella in Domestic Animals, C. A. B. I., Oxfordshire, UK, 162-192.

Uddin, M. B., Ahmed, S. S. U., Hasan, M. M., Khan, S. A., \& Mamun, M. A. (2010). Prevalence of poultry diseases at Naesingdi, Bangladesh. International Journal of Biological research, 1, 09-13.

Wray, C., Davies, R. H., \& Corkish, J. D. (1996). Enterobacteriaceae. In F.T.W. Jordan and M. Pattison (Eds). Poultry Diseases 4th edition (pp 9-43) London; Saunders company Ltd.

Yogaratnam, K. (1995). Analysis of the causes of high rates of carcass rejection at a poultry processing plant. Veterinary Record. 137(9), 215-217. doi: 10.1136/vr.137.9.215. 